\title{
Developments in therapy with monoclonal antibodies and related proteins
}

\author{
Authors: H Michael Shepard, ${ }^{A}$ Gail Lewis Phillips, ${ }^{B}$ Christopher D Thanos ${ }^{C}$ and Marc Feldmann ${ }^{D}$
}

\begin{abstract}
Monoclonal antibody therapeutics have been approved for over 30 targets and diseases, most commonly cancer. Antibodies have become the new backbone of the pharmaceutical industry, which previously relied on small molecules. Compared with small molecules, monoclonal antibodies (mAbs) have exquisite target selectivity and hence less toxicity as a result of binding other targets. The clinical value of both mAbs and ligand traps has been proven. New applications of $\mathrm{mAbs}$ are being tested and $\mathrm{mAbs}$ have now been designed to target two (bi-specific, eg TNF- $\alpha$ and IL-17) or more targets simultaneously, augmenting their therapeutic potential. Because of space limitations and the wide ranging scope of this review there are regrettably, but inevitably, omissions and missing citations. We have chosen to highlight the first successes in inflammatory diseases and cancer, but a broader overview of approved mAbs and related molecules can be found in Table 1.
\end{abstract}

KEYWORDS: Biologic therapy, cancer, inflammation, monoclonal antibodies, traps

\section{Introduction}

There has been a revolution in therapeutics over the past 20 years, due to the introduction of protein therapeutics often termed 'biologics' - into routine, mainstream medicine. Biologics are expensive and like all medicines have risks. Their advantage is exquisite specificity due to greater surface area binding, resulting in decreased 'off-target' effects as compared with most small molecule drugs.

New biologic therapies come in several basic forms, either growth factors and cytokines (such as erythropoietin, G-CSF, interferon, enzymes, factors that regulate coagulation) or, more commonly, monoclonal antibodies (mAbs) and related proteins such as 'traps' in which cytokine receptors are made soluble and fused with antibody constant regions. The latter group (mAbs and traps) have dramatically advanced the therapy of chronic inflammatory diseases and cancer. In this review, we

Authors: ${ }^{\text {A }}$ research fellow, Halozyme, San Diego, USA; ${ }^{B}$ senior scientist, Genentech Inc, San Francisco, USA; ' senior director, New Molecule Discovery, Halozyme, San Diego, USA; Demeritus professor, Kennedy Institute of Rheumatology, Oxford, UK will focus on mAbs and relatives, describing these therapeutics. The tumour necrosis factor (TNF)-blockers for autoimmune/ inflammatory diseases are the most broadly deployed (with multiple products) and have engendered a revolution in therapeutic research/development, along with rather remarkable revenues. This therapeutic revolution is based on the synergy of three scientific disciplines: immunology, molecular biology and protein engineering.

\section{Brief history}

The first mAbs were produced by Milstein and Köhler (Cambridge University), ${ }^{1}$ who won the Nobel Prize in Physiology or Medicine in 1984. mAbs were initially murine proteins and hence were immunogenic in humans and not suited for chronic therapy. This limitation was solved using molecular biology and protein engineering to create more human-like mAbs with little immunogenicity. There are several versions of $\mathrm{mAbs}$ and traps in clinical use and trials (Fig 1, Table 1). Initial attempts replaced most murine $\mathrm{Fc}$ sequences with human $\mathrm{Fc}$, a process referred to as 'chimerisation'. 2 This involves grafting the murine antigen binding Fab regions onto a human immunoglobulin (IgG) backbone. In 'humanisation', the mouse hyper-variable peptide binding loops ${ }^{3}$ are grafted onto the human IgG backbone. More recent technologies allow for generation of fully human antibodies. ${ }^{4}$

\section{Improved therapy for inflammatory/autoimmune disease}

The concept of autoimmune diseases, pioneered by Sir Frank McFarlane Burnet ${ }^{5}$ (Nobel Laureate 1960), was validated by the detection of serum autoantibodies in many diseases in the 1960s. This suggested a role for B-lymphocytes, and human leukocyte antigen (HLA) associations documented from the 1970s indicated the role of T-cells when the peptide presenting function of HLA was understood. However, these advances did not lead to new treatments at the time because of the lack of specific therapeutics.

With the advent of mAbs, the role of T-cells was tested in rheumatoid arthritis patients using lytic antibodies to CD4, without clinical benefit. ${ }^{6}$ Nor did small trials of several other anti-T-cell antibodies, such as anti-CD7. OKT3, a mouse $\mathrm{mAb}$ recognising $\mathrm{CD}^{7}$ given to reduce acute rejection in patients 


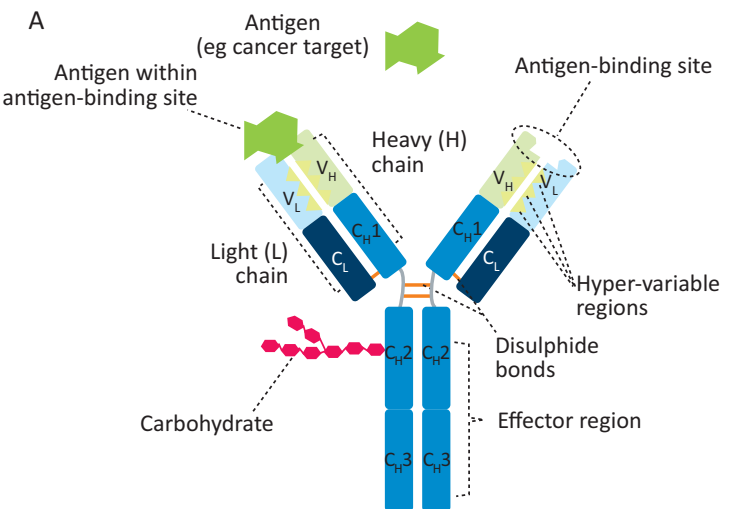

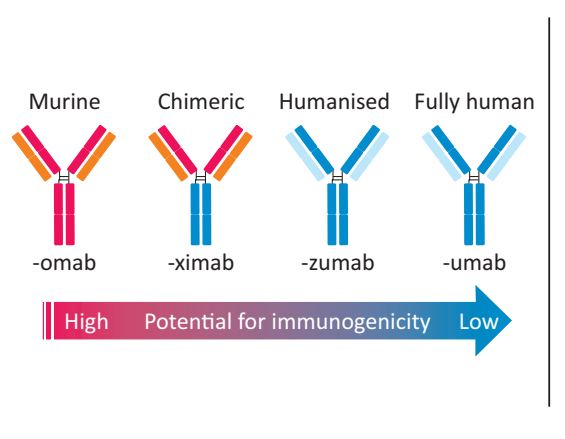

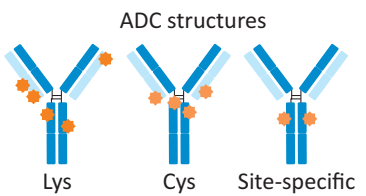

Fig 1. Monoclonal antibodies. $A$ - antibody structure showing light $(L)$ and heavy $(H)$ chains with variable $\left(V_{L}, V_{H}\right)$ and constant $\left(C_{L}, C_{H}\right)$ regions, which are connected by inter-chain disulphide bonds. Antigen binding (green symbol) occurs at $V_{H} / V_{L}$ domains, while effector functions are mediated via the $F_{C}\left(C_{H}\right)$ portion. B - increasing the amount of human sequences in a murine antibody decreases immunogenic potential. C - on an antibody-drug conjugate (ADC, cytotoxic drugs (orange, red stars) can be linked stochastically to lysine (Lys) residues or on cysteine residues either through reduction of inter-chain disulphides (Cys) or by engineering in cysteines at select conjugation sites (site-specific).

with organ transplants was the first monoclonal antibody approved for use in humans although it was later withdrawn.

\section{The success of anti-TNF therapy}

The targeting of a single pro-inflammatory cytokine, TNF, to treat a complex disease in rheumatoid arthritis (RA) where multiple pro-inflammatory cytokines were upregulated was based on work using human disease tissue by Feldmann and Maini ${ }^{8}$ and Brennan et al. ${ }^{9}$ They analysed cytokine production from joints and cytokine regulation in cultures of rheumatoid synovium in which the majority of the cells survived, producing the mediators generated in vivo. In these cultures, blocking TNF- $\alpha$ reduced the production of many other inflammatory cytokines (IL-1, IL-6, GM-CSF, IL-8 etc), ${ }^{9}$ thus defining a 'TNF-dependent cytokine cascade'. The dramatic clinical success of TNF blockade, demonstrated first in late stage RA then in earlier stage disease, also validated this concept. ${ }^{8}$ Noteworthy was the fact that tissue (bone and cartilage) damage was controlled. But also striking was the heterogeneity of the clinical response, with some individuals close to a cure and others virtually unimproved. The reasons for this are not yet clear, despite much work to try to elucidate the reasons. Genetic differences were an obvious possibility although never established, and recent clinical data demonstrating that non-responders may respond subsequently to anti-TNF has excluded it. Although anti-TNF in humans is relatively safe, ${ }^{10}$ more infections in patients occur, eg with intracellular organisms, especially tuberculosis. Many large patient registers have documented the long-term benefits of anti-TNF therapy, reducing some complications and maintaining a favourable benefit/risk ratio. ${ }^{11}$

Currently, anti-TNF is used in RA, Crohn's disease, ulcerative colitis, psoriasis, psoriatic arthritis, ankylosing spondylitis and juvenile RA; its use is now being explored in other indications (Table 1). Anti-TNF antibodies are the most successful and widely used antibody-based therapeutic. It is noteworthy that if used together with methotrexate early in the course of RA, over $50 \%{ }^{12}$ of patients can be taken off infliximab and remain virtually disease-free, even with reduced dosage of methotrexate, ${ }^{12}$ and some patients can be taken off all medication. ${ }^{13}$

In the wake of anti-TNF's success, other mAbs have also proven useful in inflammatory diseases. The antibody to the IL-6 receptor, tocilizumab (Actemra $\left.{ }^{\circledR}\right),{ }^{14}$ pioneered by Professor Tadamitsu Kishimoto, has been approved for RA and for juvenile idiopathic arthritis. Currently, other anti-cytokine antibodies to IL-6, GM-CSF and the GM-CSF receptor have been approved (siltuximab (Sylvant ${ }^{\circledR}$ ) - anti-IL-6) or are in late stage clinical trials after successful phase II studies.

Rituximab, a chimeric mAb to CD20, ${ }^{15}$ (an antigen in most B-cells although not plasma cells), was first to treat B-celldriven cancers such as non-Hodgkin lymphoma. It was pioneered by Jo Edwards for RA and subsequently approved, but was not successful in systemic lupus erythematosus (SLE) trials. Anti-CD52 (alemtuzumab) is a first generation humanised antibody, now used in multiple sclerosis. There are other antibodies approved, eg belimumab (also known as Benlysta) is an anti-BLys mAb approved for SLE, ${ }^{16}$ ustekinumab (also known as Stelara) is an antibody to the shared p40 subunit of IL-12 and IL-23 approved for psoriasis and psoriatic arthritis and potentially for Crohn's disease, ${ }^{17}$ and secukinamab (Cosentyx) is an anti-IL17A mAb approved for severe psoriasis and ankylosing spondylitis. ${ }^{18}$

Receptor IgG fusion proteins ('ligand traps') have also been generated. TNF receptor 2-Fc (etanercept, Enbrel ${ }^{\circledR}$ ) is effective and has been approved. ${ }^{19}$ Other ligand traps include rilonacept (Arcalyst - an IL-1 Trap) and the anti-angiogenesis vascular endothelial growth factor trap (aflibercept (Eylea ${ }^{\circledR}$ ) for retinopathies and ziv-aflibercept (Zaltrap ${ }^{\circledR}$ ) for colorectal cancer) (Table 1). Abatacept (Orencia ${ }^{\circledR}$ ) and belatacept (Nolojix ${ }^{\circledR}$ ) are CTLA4-Fc fusion proteins that inhibit antigen presentation to T-cells and are effective in RA.

\section{Monoclonal antibodies in cancer therapy}

mAb discovery: a case study of trastuzumab (Herceptin)

Modern mAb therapy of solid tumours was initiated by the humanised human epidermal growth factor receptor 2 (HER2) 


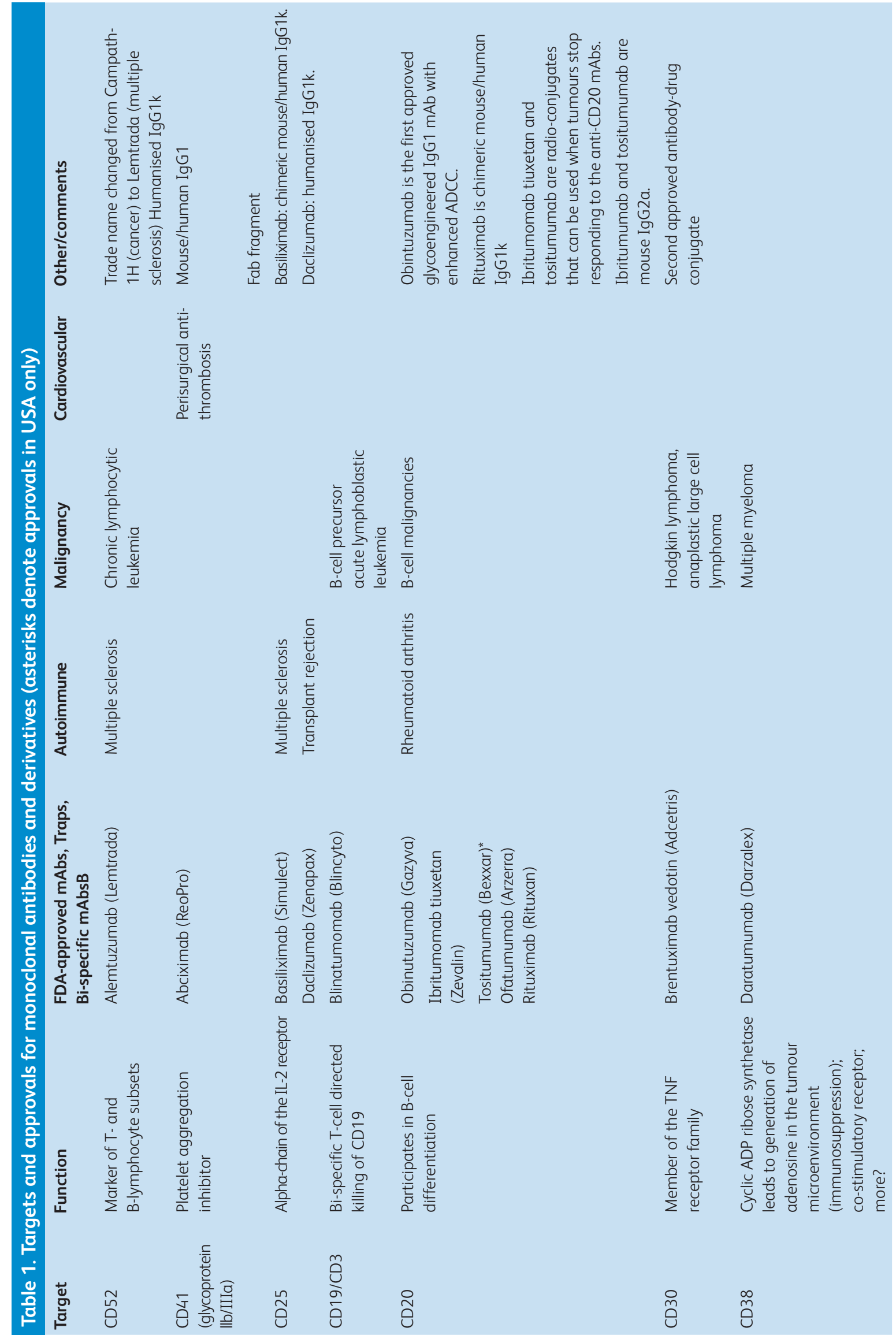




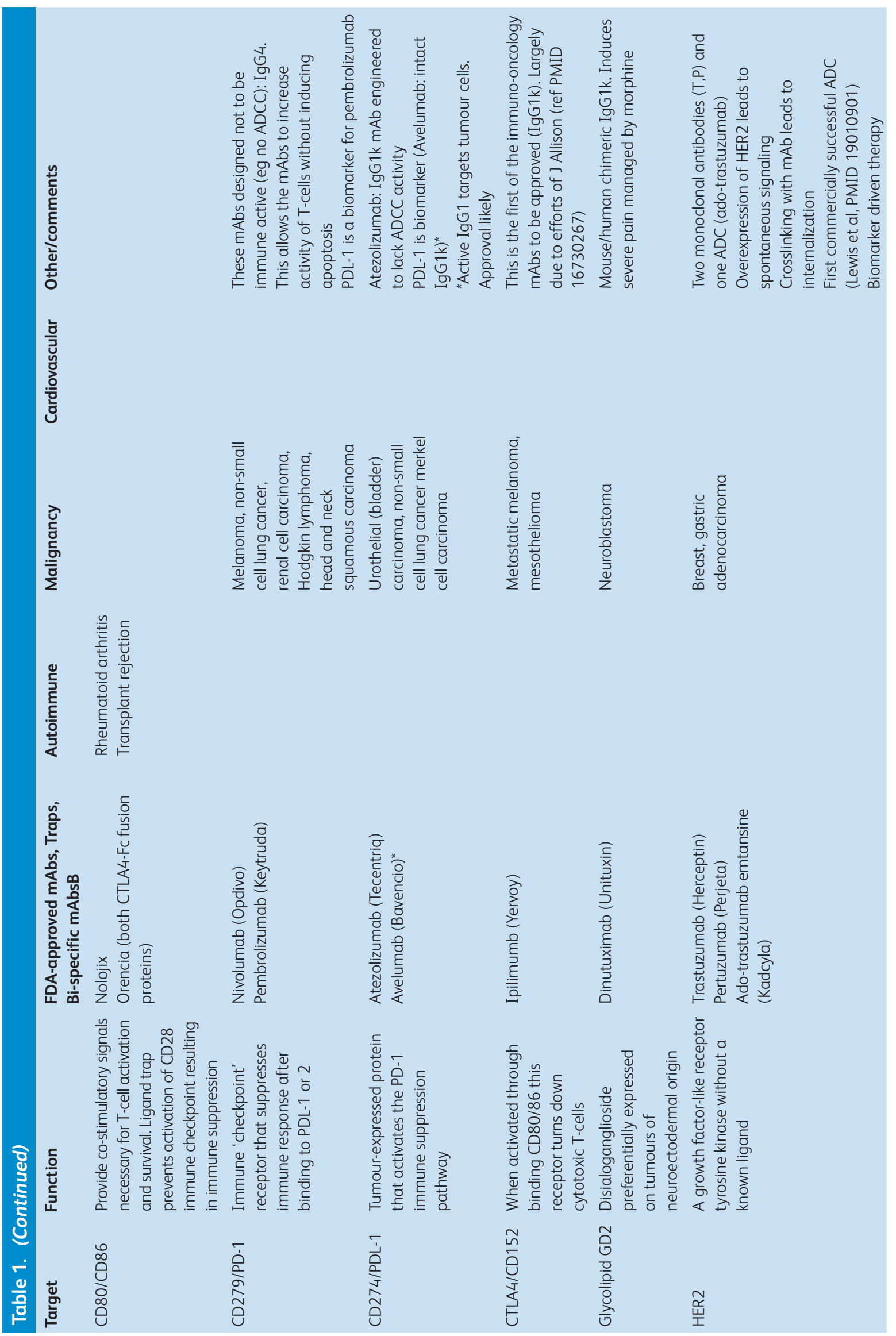




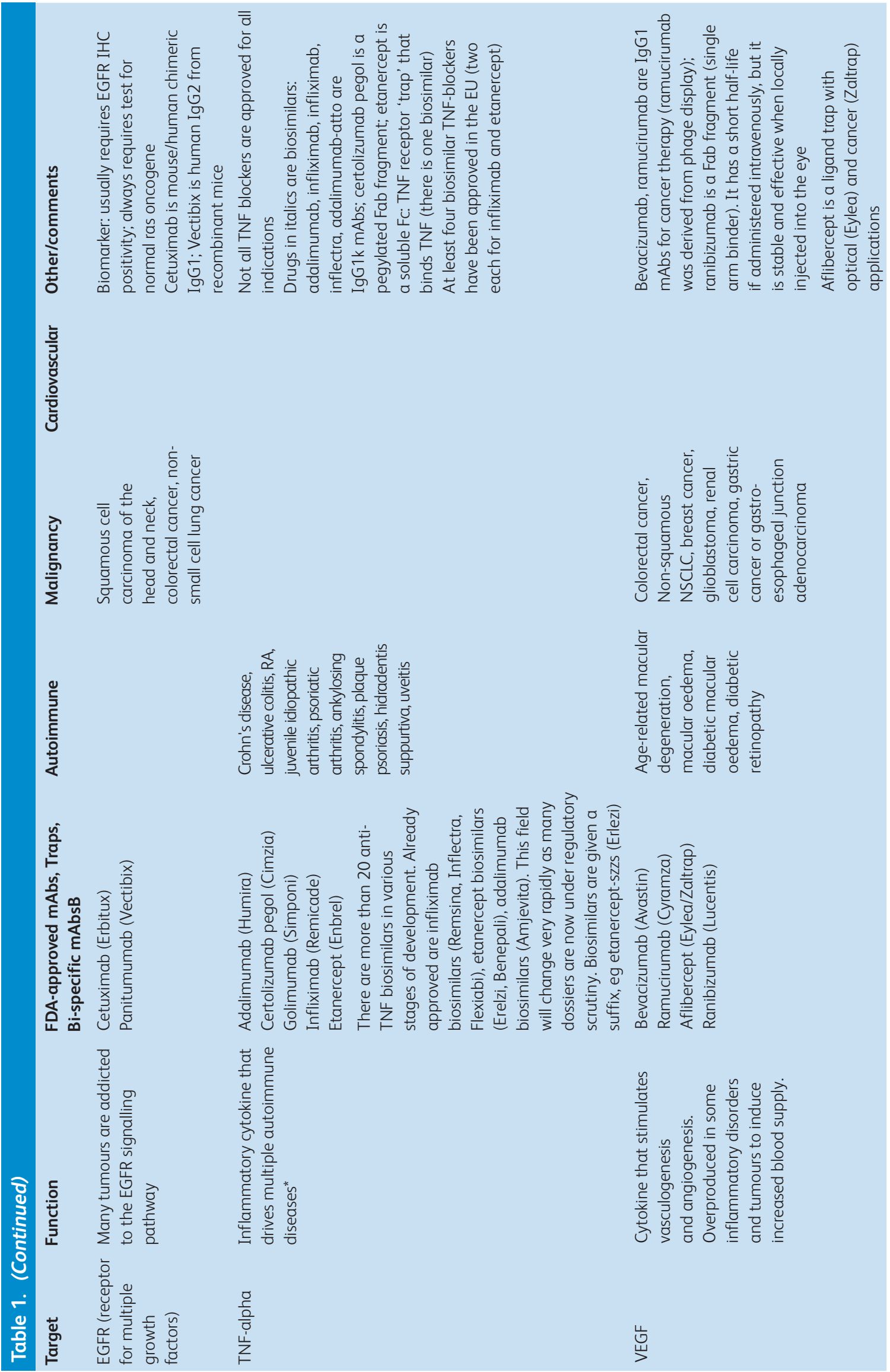




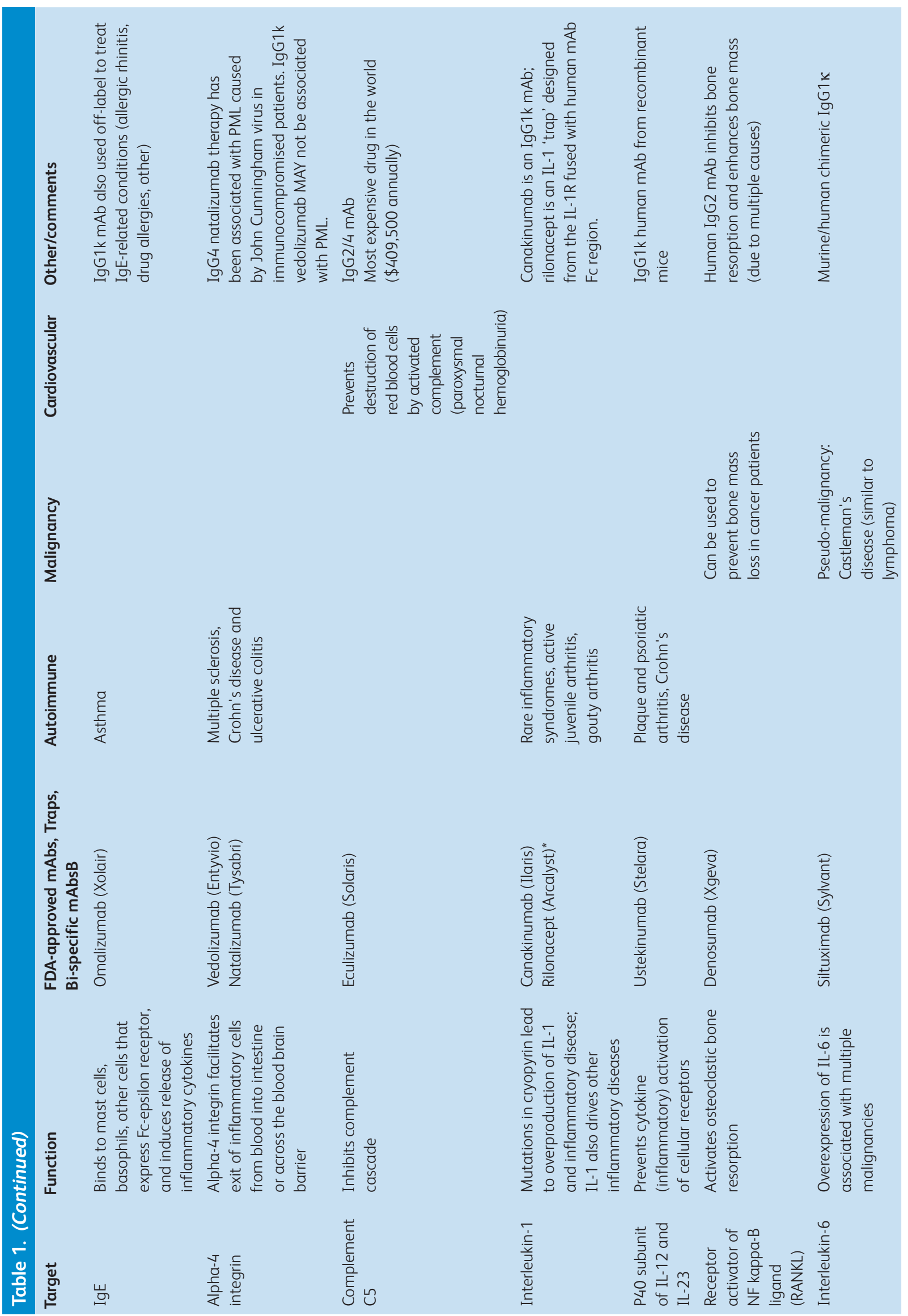



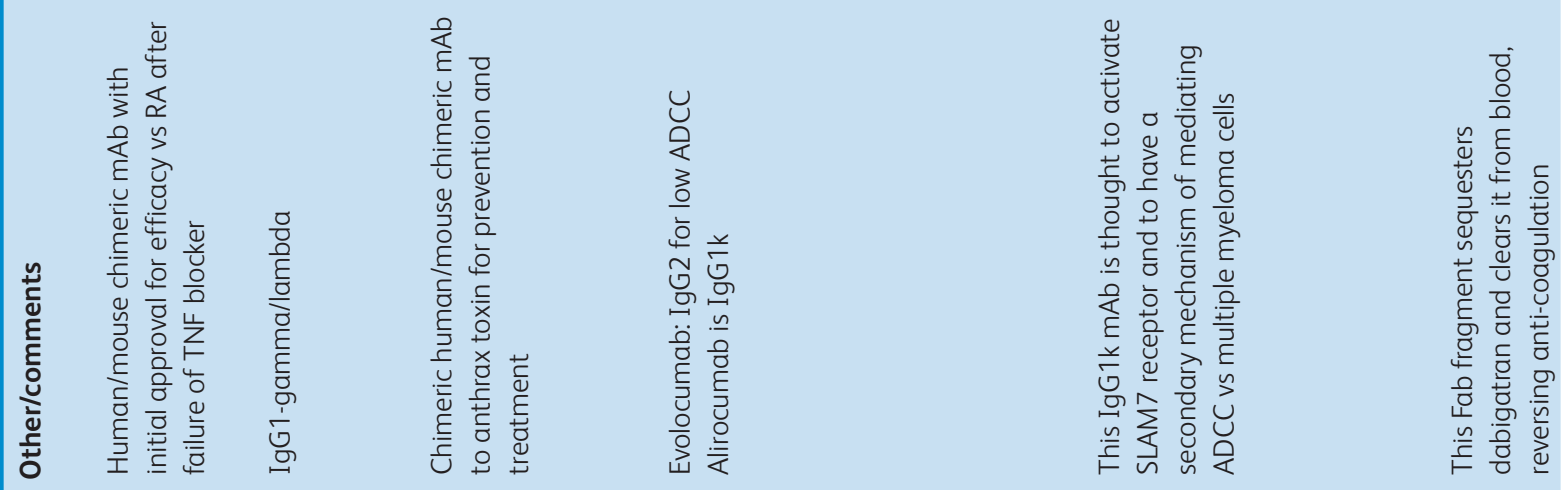

흘
ํㅡㄹ
음
흔

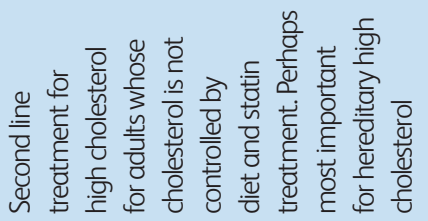

ह
$\frac{0}{0}$
है
$\frac{0}{0}$
$\frac{\text { Dे }}{\frac{1}{2}}$
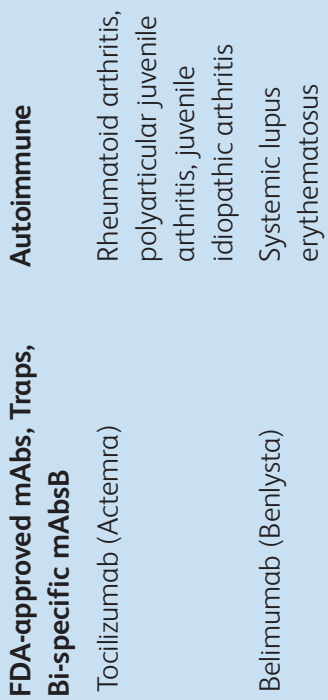

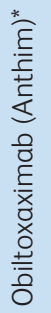

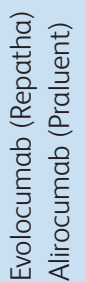

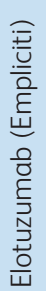
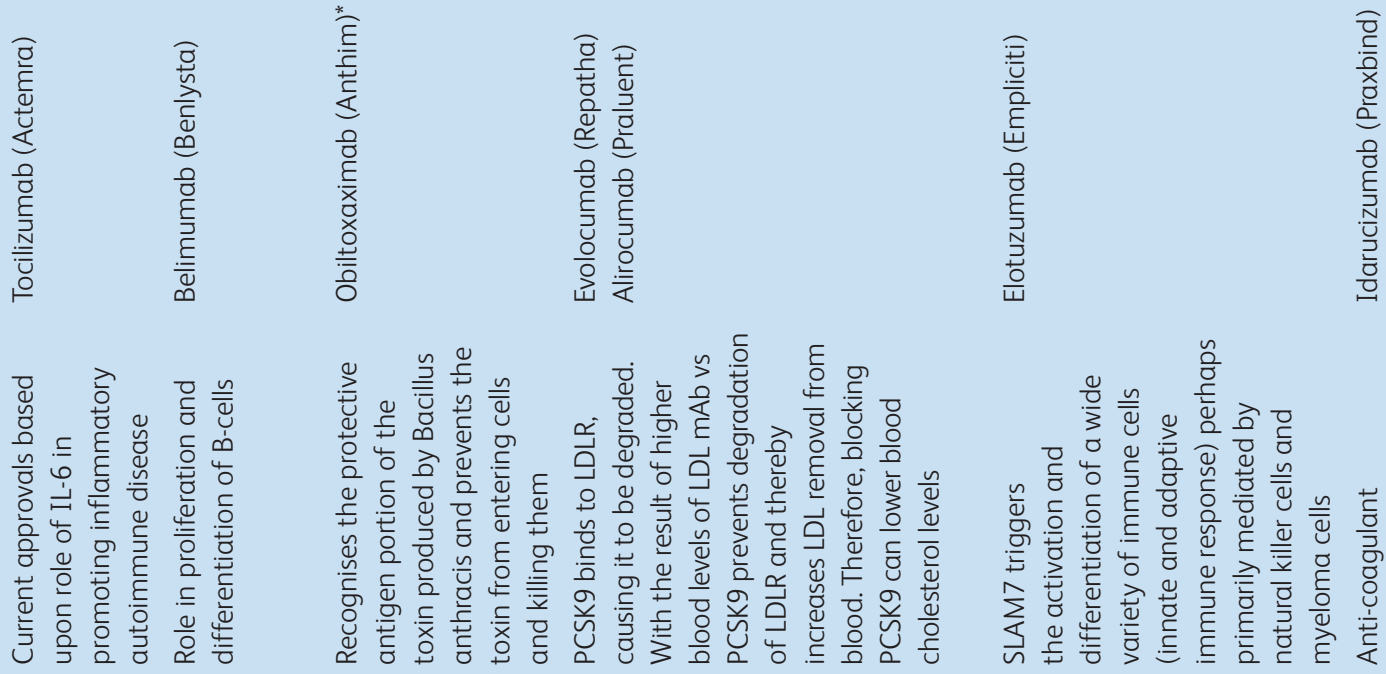


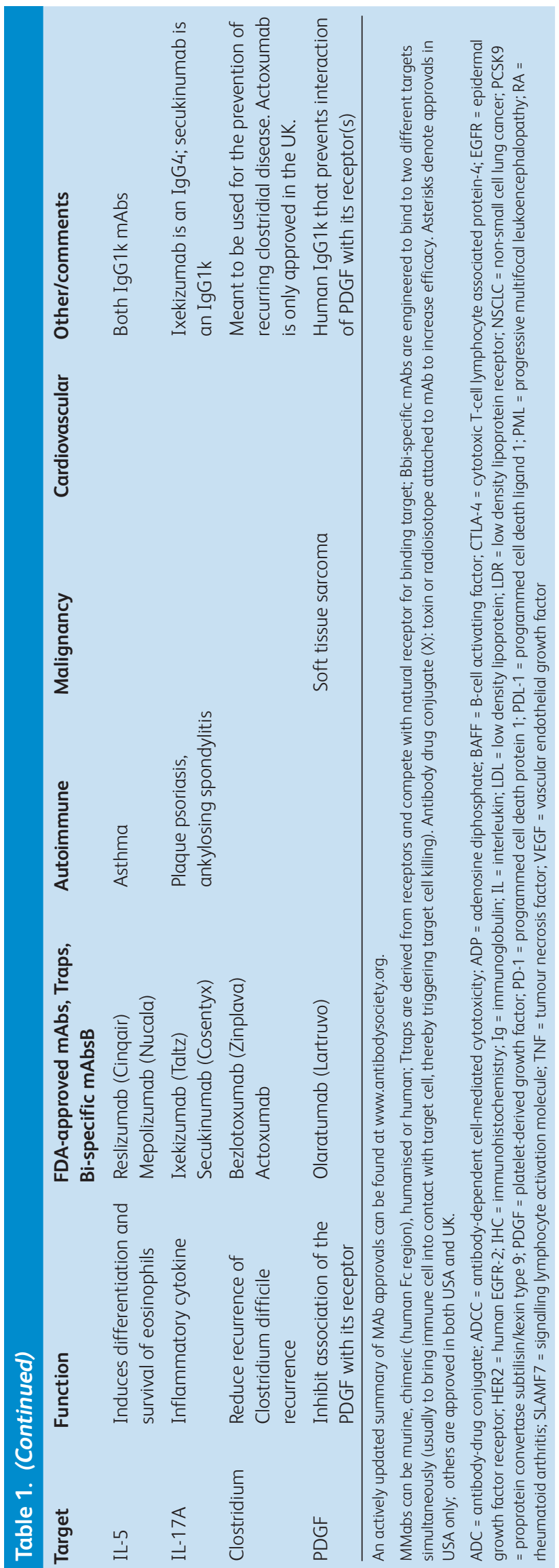


mAb trastuzumab (Herceptin $\left.{ }^{\circledR}\right) .{ }^{20}$ The rigorous science that laid the foundation for this breakthrough $\mathrm{mAb}$ also initiated personalised/biomarker driven drug discovery and treatment in oncology.

Trastuzumab, the first successful monoclonal anti-cancer antibody to be successful against solid tumours, is well tolerated in patients. The pathway leading to TNF-resistance of most tumour cell lines ${ }^{21}$ was unraveled by collaboration between the Shepard (Genentech) and Schreiber laboratories (Chicago), which revealed that macrophages kill tumour cells largely by secreting TNF. ${ }^{22}$ They hypothesised that if tumour resistance to macrophages could be reversed, the tumour would become sensitive to killing by host defence. Macrophage (or TNF)-resistant tumour cells implanted into syngeneic mice formed aggressive tumours, while their TNF-sensitive parental cells regressed. ${ }^{21}$

The mechanism of TNF-resistance of tumours needed to be widespread since most tumour cell lines were resistant. Sporn and Todaro's autocrine growth factor hypothesis ${ }^{23}$ of malignant transformation involving autocrine stimulation by transforming growth factors seemed plausible. Various growth factors were combined with TNF on TNF-sensitive tumour cell lines and growth factors that activated receptor tyrosine kinases converted TNF-sensitive tumour cells to TNF-resistant cells. ${ }^{24}$ Host defence was completely subverted and the growth inhibitor (TNF) even became a growth factor. ${ }^{25}$

Slamon et $a l^{26,27}$ and Zhou et $a l^{28}$ reported that overexpression of the receptor tyrosine kinase HER2 in breast and ovarian cancers was associated with more aggressive disease contemporaneously with Shepard's demonstration that overexpression of HER2 induced resistance to $\mathrm{TNF}^{29}$ and that mAbs to HER2 inhibited growth of HER2-overexpressing tumours in vitro and in vivo. ${ }^{30-32}$ The lead antibody, MuMAb4D5 - the murine partent of trastuzumab, ${ }^{24}$ was ineffective on normal cells or tumour cells not overexpressing HER $2 .^{26,33}$ Anti-HER2 also validated the importance of stability of the target itself as HER2 is indispensable in driving disease in subsets of breast, gastric and ovarian cancers. These findings laid the foundation for the success of trastuzumab and subsequently for pertuzumab, ${ }^{34}$ which binds a separate epitope on HER2, and then trastuzumab emtansine, an antibody drug conjugate. ${ }^{35}$ The clinical success of trastuzumab required the co-development of two novel companion diagnostic approaches: immunohistochemistry and fluorescence in situ hybridisation for selecting patients most likely to respond. ${ }^{36}$ This was a new idea at the time, but is now a routine part of most cancer drug discovery and therapeutic programmes. Finally, this $\mathrm{mAb}$ showed that antibody therapy was feasible in solid tumours, overcoming problems such as high internal tumour pressure, which causes vascular collapse and reverse flow of fluid in solid tumours. ${ }^{37}$

MuMAb4D5 was humanised using a consensus human variable domain sequence from the Kabat database, together with human immunoglobulin constant domain (IgG1, kappa) sequences. ${ }^{38}$ This resulted in the synthesis of a recombinant antibody, non-existent in nature, with almost 95\% human sequence, reducing concerns related to immunogenicity. The humanised antibody has three mechanisms of action dependent upon upregulated HER2:

1 growth inhibition

2 antibody-dependent cell-mediated cytotoxicity (ADCC)

3 induction of TNF sensitivity. ${ }^{20,30}$
The strategy employed in the development of trastuzumab is now widely employed in cancer drug discovery (Fig 2). Very recently in clinical trials, a combination of trastuzumab and another anti-HER $2 \mathrm{mAb}$ (pertuzumab ${ }^{30}$ ) generated a complete pathological response in approximately $50 \%$ of HER2-positive patients, ${ }^{39}$ which is a previously unheard of therapeutic advance in the treatment of breast cancer. The HER2 programme proved that mAbs have a place in therapy of solid tumours and that tyrosine kinase oncogenes were viable targets in cancer.

Not all successful mAb therapeutics followed this pathway of discovery. The first approved mAbs targeted membrane proteins shared between haematologic malignancies and their precursor immune cell subsets (eg alemtuzumab (Campath ${ }^{\circledR}$ ) - an anti-CD52, rituximab (Rituxan ${ }^{\circledR}$ ) - an anti-CD20). These mAbs ablate both normal and cancer cells. Alemtuzumab was the first humanised $\mathrm{mAb}$ therapeutic, depleting lymphocytes, monocytes and dendritic cells, useful in diseases such as chronic lymphocytic leukemia. Similarly, rituximab depletes CD20-expressing B-cells. Resistance to these mAb therapeutics occurs with the loss of the target as neither CD52 nor CD20 is essential for malignant growth. These mAbs have toxicity issues due to massive depletion of immune cells, potentially causing 'cytokine release syndrome' or 'tumour lysis syndrome' - a 'cytokine storm' resulting from aberrant immune activation attributable to cellular debris activating 'danger receptors'. Despite these issues, both rituximab and alemtuzumab are successful drugs and often lead to disease regression.

More recently, Jim Allison and other cancer researchers discovered the utility of mAbs targeting 'immune checkpoints'. By inhibiting these pathways (eg programmed cell death protein 1 (PD-1)/programmed cell death ligand 1 (PD-L1) or cytotoxic T-cell lymphocyte associated protein-4), tumour-associated immune suppression can be reversed with clinically effective immune cell attack on tumours in about $20 \%$ cases. Some patients have had dramatic improvements, notably in metastatic melanoma, and there is no doubt that this is a major step forward. Not unexpectedly there are immune-mediated diseases in a large fraction (about 30\%) of treated patients, but this field of $\mathrm{mAb}$ therapy is growing very rapidly. CTLA-4 expressed on regulatory T-cells exerts immune suppressive activity. Anti-CTLA-4 prevents CTLA-4 from inhibiting immunity. ${ }^{40} \mathrm{PD}-1$ is present on 'exhausted' T-cells; anti-PD-1 reactivates them. The first approvals of this new class of anti-cancer mAbs were in melanoma with ipilimumab (anti-CTLA-4, Yervoy ${ }^{\circledR}$ ) and pembrolizumab (anti-PD1, Keytruda ${ }^{\circledR}$ ) in 2015, followed by atezolizumab (anti-PD-L1, Tecentriq ${ }^{\circledR}$ ) for non-small cell lung cancer and bladder cancer. Checkpoint inhibitor mAbs, such as antiOX40, can also be agonistic. ${ }^{40}$

\section{Other antibody-related approaches and mechanisms}

Therapeutic antibodies: structural marvels that mediate multiple functional effects

Antibodies have evolved over the past 400 million years to provide broad ranging host defence in all vertebrates. Thus, it is not surprising that engineered antibodies have emerged as one of the main sources of new medicines. Antibodies evolved to possess several important functional properties exploited by recombinant $\mathrm{mAb}$ therapeutics, such as exquisite specificity 


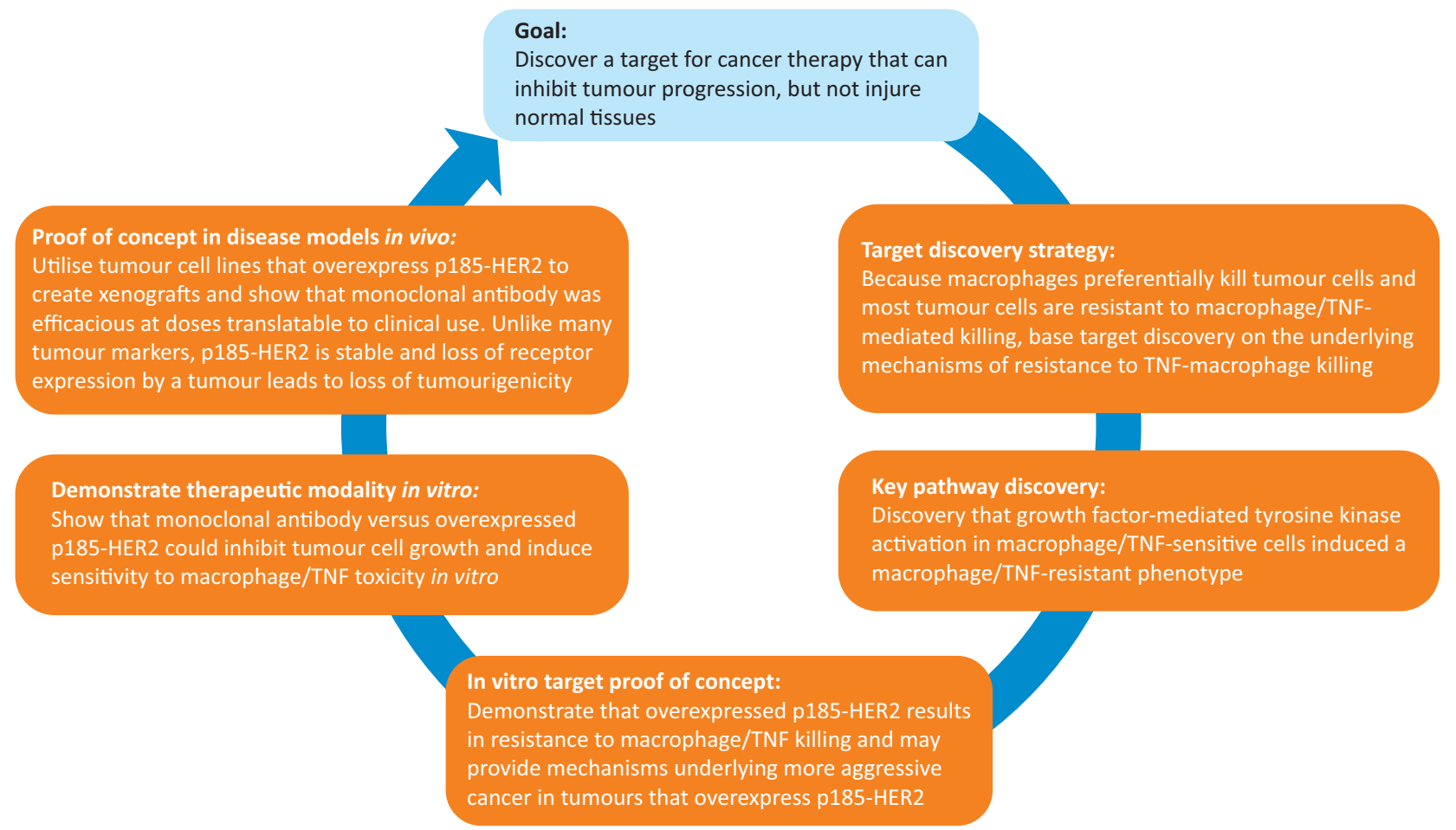

Fig 2. Strategy and key steps for development of trastuzumab, from target discovery to in vitro and in vivo proof of concept studies. HER2 = human epidermal growth factor receptor 2; TNF = tumour necrosis factor

and affinity toward their antigen targets, recruiting immune system effector components and a long serum half-life.

Antibodies possess a unique tertiary domain structure, folding into a complex quaternary structure. Human serum immunoglobulin is approximately $80 \%$ IgG, as are most approved therapeutic antibodies. These complex proteins (approximately $150 \mathrm{kDa}$ ) comprise four polypeptide chains -2 heavy and 2 light chains - with disulphide bonds providing significant rigidity. The heavy chain consists of a variable domain $(\mathrm{VH})$ and three constant domains $(\mathrm{CH} 1, \mathrm{CH} 2$ and $\mathrm{CH} 3$ ). The light chain consists of a variable domain (VL) and a constant domain (CL) (Fig 1A). IgG antibodies are bivalent and have post-translational modifications. Glycosylation in the Fc domain also helps to provide stability and modulates properties such as binding to Fc receptors. ${ }^{41}$

\section{The antibody/antigen interaction}

Several technologies are used to identify novel antibodies: hybridomas, genetically modified mice with human immunoglobulin sequences and phage or yeast display. B-cells from a mouse injected with an antigen are fused with immortalised B-cell myeloma cells to make hybridomas. To improve their efficacy in patients, protein engineers created chimeric antibodies containing human constant domains and murine variable domains, which reduce immunogenicity and activate effector functions (Fig 1). Approved chimeric antibodies include Remicade ${ }^{\circledR}$ (infliximab), Erbitux ${ }^{\circledR}$ (cetuximab) and Rituxan ${ }^{\circledR}$ (rituximab). As an example of a 'humanised' antibody Herceptin ${ }^{\circledR}$ (trastuzumab) was isolated from a murine hybridoma and then 'humanised' where all but the binding site to the HER2 antigen was changed to a human sequence (Fig 1). Genetically engineered mice have been developed that can make fully human antibodies, eg Vectibix ${ }^{\circledR}$ (panitumumab) - anti-epidermal growth factor receptor. Another important approach employs synthetic (human) antibody libraries that are displayed on the surface of yeast or phage, which is useful for less immunogenic targets. There are advantages and limitations to each of these methods; therefore, antibody discovery groups will attempt multiple approaches in parallel against a particular target.

\section{Antibody effector function}

Immunoglobulins can stimulate immune defence mechanisms through ADCC, antibody-dependent cellular phagocytosis and complement-dependent cytotoxicity. During ADCC, immune cells - usually natural killer (NK) cells - lyse a target cell with an IgG bound to a cell surface target. CD16 Fc receptors expressed on NK cells bind to the Fc region of the IgG, forming a lytic synapse between the NK cell and the target cell, destroying the target cell. During complement-dependent cytotoxicity, complement is recruited to the IgG-bound surface pathogen through Clq binding to the antibody Fc domain, triggering proteolytic events, yielding a membrane attack complex that disrupts cellular membranes with cell death. Many therapeutic antibodies use ADCC as a key mechanism of action, eg trastuzumab and rituximab. Methods have been developed for increasing or decreasing antibody effector function, the number of epitope binding sites or attaching cytotoxic drugs. Some of these strategies are shown in Fig 1. 


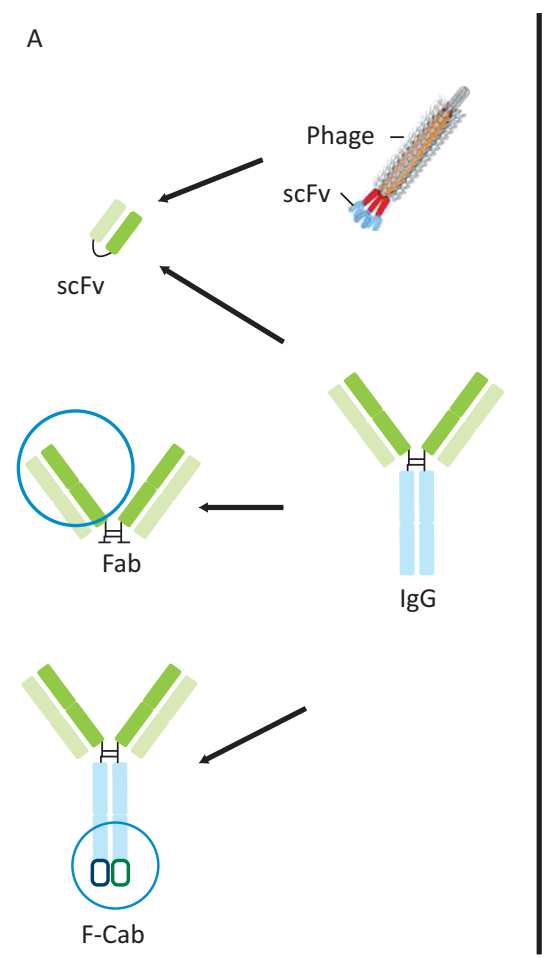

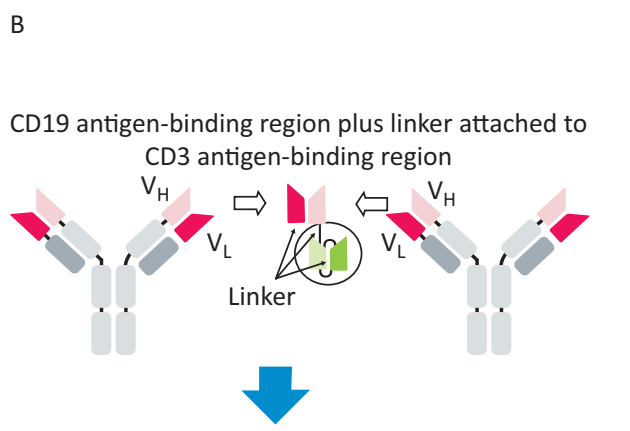

Bi-specific T-cell engager (BiTE)

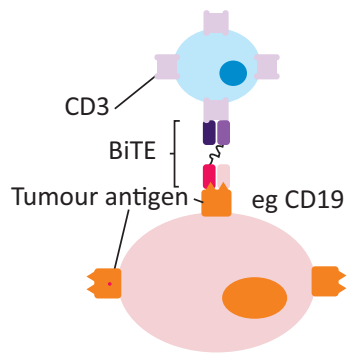

C

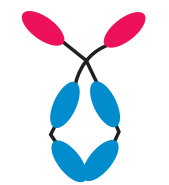

Camelid antibodies

Fig 3. Emerging antibody technologies. A - derivatives of classical mAbs: scFv, Fab, and F-Cab antibody formats; $B$ - engineered bi-specific mAbs: structure and mechanism of a bi-specific T-cell engaging (BiTE) antibody; $\mathrm{C}$ - novel mAb frameworks: unique structure of camelid antibodies. $\mathrm{mAb}=\mathrm{monoclonal}$ antibody

\section{Antibody pharmacokinetics}

Antibodies have a long serum half-life, typically lasting 2-4 weeks in circulation. Antibody binding the Fc domain of the neonatal Fc receptor, FcRn, recycles the antibody, protecting it from other clearance mechanisms. This long half-life with less frequent dosing is often more favourable for patients when extended drug function is needed. Antibody dosing is typically intravenous or subcutaneous. Oral administration is not feasible because of rapid degradation of the antibody in the gut. In addition, therapeutic antibodies cannot pass in appreciable quantities through the intact blood-brain barrier.

\section{Antibody-drug conjugates: using antibodies for tumour-} selective delivery of cytotoxics

The therapeutic use of antibody-drug conjugates (ADCs) is based on antibody-mediated tumour-selective delivery of potent cytotoxic compounds. This relies on antibody-induced receptor internalisation, followed by trafficking of the ADC to the lysosomes where the cytotoxic drug is released from the ADC. The free drug (inside the target cell) initiates its antitumour activity. Stability of the linker that joins the antibody and cytotoxic agent is key to both efficacy and safety. The linker must be stable in the circulation to prevent premature release of the cytotoxic agent, yet allow release of the cytotoxic drug within the tumour cell. The most common linkers are cleavable linkers such as peptides, cleaved by proteases, or disulphide linkers, which undergo reduction to release the drug within the lysosome. ADCs can also utilise a stable or non-cleavable linker, the free drug is released in the lysosome after lysosomal degradation of the entire ADC molecule.
Despite decades of intense research and development, only three ADCs have gained marketing approval. The first, gemtuzumab ozogamicin (Mylotarg ${ }^{\circledR}$ ), was approved then taken off the market. Significant advances were subsequently made in ADC linker design and conjugation technologies, yielding two additional approved ADCs, one for CD30positive Hodgkin lymphoma and anaplastic large cell lymphoma (brentuximab vedotin (Adcentris ${ }^{\circledR}$ ), and one for metastatic breast tumours overexpressing HER2/neu trastuzumab emtansine (Kadcyla $\left.{ }^{\circledR}\right)$. The anti-CD30 antibody component of brentuximab vedotin is linked to the tubulin polymerisation inhibitor mono-methyl auristatin $\mathrm{E}$ through a protease cleavable linker, valine-citrulline. Trastuzumab emtansine is comprised of trastuzumab covalently linked to the maytansinoid derivative, DM1, through a stable, non-cleavable linker. Current research suggests that more efficacious and better tolerated ADCs will be developed, which will provide greater clinical benefit to cancer patients.

\section{Emerging antibody technologies}

The Fab fragment (Fig 3A) used in ranibizumab (Lucentis) ${ }^{42}$ can be manufactured in Escherichia coli. The short halflife of Fabs can be remedied by polyethylene glycol used in certilizumab pegol, Cimzia ${ }^{\circledR}{ }^{43}$

Until recently, it has been difficult to synthesise bi-specific mAbs. Now various types are possible. Bi-specific T-cell engaging (BiTE) antibodies consist only of the variable regions from distinct antibodies (Fig 3B) and are the format of the first approved bi-specific antibody, catumaxomab (Removab $\left.{ }^{\circledR}\right)$, for malignant ascites. 


\section{Antibody-based cellular immunotherapies}

A new class of antibody-based therapeutics called 'chimeric antigen receptor T-cells' are emerging in cancer. An antibodylike antigen binding region is fused with signalling components of the T-cell receptor and the chimeric gene is inserted into the patient's own T-cells. When the T-cells recognise their target on tumour cells, the T-cell cytotoxic response is activated, lysing the cancer cells. ${ }^{43}$ Using CTL019, a chimeric antigen receptor T-cell engineered to target cancer cells that express the CD19 protein present on acute lymphoblastic leukemia cells, 19 of 22 paediatric patients with lethal acute lymphoblastic leukaemia experienced remission. ${ }^{44}$ However, this treatment upregulates inflammatory cytokines, with consequent toxicity.

\section{Conclusions}

$\mathrm{mAb}$ therapeutics have been approved for 33 targets in more than 37 distinct diseases (Table 1), most commonly for cancer (27 approvals). The clinical value of both mAbs and ligand traps has been proven. The most targeted pathway is the TNF pathway, now employed to treat nine different indications and likely to expand as TNF is found to be a driver of additional diseases and conditions, including postoperative cognitive decline ${ }^{45}$ and fibrosis. ${ }^{46}$ New applications of mAbs are being tested, with approvals in bone metabolism ${ }^{47}$ and hypercholesterolemia. ${ }^{48}$

Antibodies have become the new backbone of the pharmaceutical industry, which previously relied on huge libraries of small molecules. Compared with small molecules, mAbs have an exquisite target selectivity and, therefore, less toxicity attributable to binding to other targets. mAbs have now been designed to target two or more targets simultaneously, augmenting the therapeutic potential. We are only just at the beginning of the $\mathrm{mAb}$ therapeutic era.

\section{Conflicts of interest}

GLP is an employee of Genentech and owns Roche stock. CT and HMS are employees of Halozyme and own Halozyme stock. MF is one of the inventors of anti-TNF therapy and receives royalties on combination therapy.

\section{Author contributions}

All authors wrote part of the review, read all of it and approved the final version.

\section{References}

1 Köhler G, Milstein C. Derivation of specific antibody-producing tissue culture and tumor lines by cell fusion. Eur J Immunol 1976;6:511-9.

2 Morrison SL, Johnson MJ, Herzenberg LA, Oi VT. Chimeric human antibody molecules: mouse antigen-binding domains with human constant region domains. Proc Natl Acad Sci USA 1984:81:6851-2.

3 Jones PT, Dear PH, Foote J, Neuberger MS, Winter G. Replacing the complementarity-determining regions in a human antibody with those from a mouse. Nature 1986;321:522-5.

4 An Z. Monoclonal antibodies - a proven and rapidly expanding therapeutic modality for human diseases. Protein Cell 2010;1:319-30.

5 Burnet FM. Immunological recognition of self. Science 1961;133:307-11.
6 Choy EH, Kingsley GH, Panayi GS. Anti-CD4 monoclonal antibodies in rheumatoid arthritis. Springer Semin Immunopathol 1998;20:261-73.

7 Van Wauwe JP, De Mey JR, Goossens JG. OKT3: a monoclonal antihuman $\mathrm{T}$ lymphocyte antibody with potent mitogenic properties. $J$ Immunol 1980;124:2708-13.

8 Feldmann M, Maini RN. Lasker Clinical Medical Research Award. TNF defined as a therapeutic target for rheumatoid arthritis and other autoimmune diseases. Nature Medicine 2003;9:1245-50.

9 Brennan FM, Chantry D, Jackson A, Maini RN, Feldmann M. Inhibitory effect of TNF antibodies on synovial cell interleukin-1 production in rheumatoid arthritis. Lancet 1989;2:244-7.

10 Leombruno JP, Einarson TR, Keystone EC. The safety of antitumour necrosis factor treatments in rheumatoid arthritis: meta and exposure-adjusted pooled analyses of serious adverse events. Ann Rheum Dis 2009;68:1136-45.

11 Kievit W, Fransen J, Adang EM et al. Long term effectiveness and safety of TNF-blocking agents in daily clinical practice: results from the Dutch Rheumatoid Arthritis Monitoring register. Rheumatol 2011;50:196-203.

12 van der Bijl AE, Goekoop-Ruiterman YP, de Vries-Bouwstra $\mathrm{JK}$, et al. Infliximab and methotrexate as induction therapy in patients with early rheumatoid arthritis. Arthr Rheum 2007;56:2129-34.

13 Quinn MA, Conaghan PG, O'Connor PJ et al. Very early treatment with infliximab in addition to methotrexate in early, poor-prognosis rheumatoid arthritis reduces magnetic resonance imaging evidence of synovitis and damage, with sustained benefit after infliximab withdrawal. Results from a 12-month randomized, double-blind, placebo-controlled trial. Arthr Rheum 2005;52:27-35.

14 Kang S, Tanaka T, Kishimoto T. Therapeutic uses of anti-interleukin-6 receptor antibody. Int Immunol 2015;27:21-9.

15 Cohen MD, Keystone E. Rituximab for rheumatoid arthritis. Rheumatol Ther 2015;2:99-111.

16 Hahn BH. Belimumab for systemic lupus erythematosus. New Engl J Med 2013;368:1528-35.

17 Feagan BG, Sandborn WJ, Gasink C et al. Ustekinumab as induction and maintenance therapy for Crohn's Disease. New Engl J Med 2016;375:1946-60.

18 Baeten D, Sieper J, Braun J et al. Secukinumab, an interleukin-17A inhibitor, in Ankylosing Spondylitis. 2015; New Engl J Med. 373: 2534-48.

19 Weinblatt ME, Moreland LW, Westhovens R et al. Safety of abatacept administered intravenously in treatment of rheumatoid arthritis: integrated analyses of up to 8 years of treatment from the abatacept clinical trial program. J Rheumatol 2013;40:787-97.

20 Carter P, Presta L, Gorman CM et al. Humanization of an antip185HER2 antibody for human cancer therapy. Proc Natl Acad Sci USA 1992;89:4285-9.

21 Sugarman BJM, Aggarwal BB, Hass PE et al. Recombinant human tumour necrosis factor-alpha: effects on proliferation of normal and transformed cells in vitro. Science 1985;230:943-5.

22 Urban JL, Shepard HM, Rothstein JL, Sugarman BJ, Schreiber $\mathrm{H}$. Tumor necrosis factor: a potent effect molecule for tumor cell killing by activated macrophages. Proc Natl Acad Sci USA 1986;83:5233-7.

23 Sporn MB, Todaro GJ. Autocrine secretion and malignant transformation of cells. N Engl J Med 1980;303:878-80.

24 Sugarman BJ, Lewis GD, Eessalu TE, Aggarwal BB, Shepard HM. Effects of growth factors on the anti proliferative activity of tumor necrosis factors. Cancer Res 1987;47:780-6.

25 Lewis GD, Aggarwal BB, Eessalu TE, Sugarman BJ, Shepard HM. Modulation of the growth of transformed cells by human tumor necrosis factor-alpha and interferon-gamma. Cancer Res 1987;47:5382-5. 
26 Slamon DJ, Clark GM, Wong SG et al. Human breast cancer: correlation of relapse and survival with amplification of the HER-2/neu oncogene. Science 1987;235:177-82.

27 Slamon DJ, Godolphin W, Jones LA et al. Studies of the HER-2/ neu proto-oncogene in human breast and ovarian cancer. Science 1989;244:707-12.

28 Zhou D, Battifora H, Yokota J, Yamamoto T, Cline MJ. Association of multiple copies of the c-erbB-2 oncogene with spread of breast cancer. Cancer Res 1987;47:6123-5.

29 Hudziak RM, Lewis GD, Shalaby MR et al. Amplified expression of the HER2/ERBB2 oncogene induces resistance to tumor necrosis factor alpha in HIH 3T3 cells. Proc Natl Acad Sci USA 1988:85:5102-6.

30 Lewis GD, Figari I, Fendly B et al. Differential responses of human tumor cell lines to anti-p185HER2 monoclonal antibodies. Cancer Immunol Immunother 1993;37:255-63.

31 Ceran C, Cokol M, Cingoz S et al. Novel anti-HER2 monoclonal antibodies: synergy and antagonism with tumor necrosis factoralpha. BMC Cancer 2012;12:450.

32 Sobol RE, Astarita RW, Hofeditz C et al. Epidermal growth factor receptor expression in human lung carcinomas defined by a monoclonal antibody. J Natl Cancer Inst 1987:79:403-7.

33 Varley JM, Swallow JE, Brammer WJ, Whittaker JL, Walker RA. Alternations to either c-erbB-2(neu) or c-myc proto-oncogenes in breast carcinomas correlate with poor short-term prognosis. Oncogene 1987;1:423-30.

34 Adams CW, Allison DE, Flagella K et al. Humanization of a recombinant monoclonal antibody to produce a therapeutic HER dimerization inhibitor, pertuzumab. Cancer Immunol Immunother 2006;55;717-27.

35 Lewis Phillips GD, Li G, Dugger DL et al. Targeting HER2-positive breast cancer with trastuzumab-DM1, an antibody-cytotoxic drug conjugate. Cancer Res 2008;68:9280-90.

36 Lebeau A, Deimling D, Kaltz C et al. Her-2/neu analysis in archival tissue samples of human breast cancer: comparison of immunohistochemistry and fluorescence in situ hybridization. J Clin Oncol 2001;19:354-63.

37 Jain RK. Vascular and interstitial barriers to delivery of therapeutic agents in tumors. Cancer Metastasis Rev 1990;9;253-66.

38 Johnson G, Wu TT. Kabat database and its applications: 30 years after the first variability plot. Nucleic Acids Res 2000;28:214-8.
39 Tiwari SR, Mishra P, Raska P et al. Retrospective study of the efficacy and safety of neoadjuvant docetaxel, carboplatin, trastuzumab/pertuzumab (TCH-P) in nonmetastatic HER2-positive breast cancer. Breast Cancer Res Treat 2016;258:189-93.

40 Mahoney KM, Rennert PD, Freeman GJ. Combinatino cancer immunotherapy and new immunomodulatory targets. Nat Rev Drug Discov 2015;14:561-84.

41 Bournazos S, Ravetch JV. Fc receptor pathways during active and passive immunization. Immunol Rev 2015;268:88-103.

42 Ferrara N, Damico L, Shams N, Lowman H, Kim R. Development of ranibizumab, an anti-vascular endothelial growth factor antigen binding fragment, as therapy for neovascular age-related macular degeneration. Retina 2006;26:859-70.

43 Choy EH, Hazleman B, Smith M et al. Efficacy of a novel PEGylated humanized anti-TNF fragment (CDP870) in patients with rheumatoid arthritis: a phase II double-blinded, randomized, dose-escalating trial. Rheumatology 2002;41:1133-7.

44 Maude SL, Frey N, Shaw PA, Aplenc R, Barrett DM. Chimeric antigen receptor $\mathrm{T}$ cells for sustained remissions in leukemia. $N$ Engl J Med 2014;371:1507-17.

45 Terrando N, Monaco C, Ma D et al. Tumor necrosis factor-alpha triggers a cytokine cascade yielding postoperative cognitive decline. Proc Natl Acad Sci USA 2010;107:20518-22.

46 Glass GE, Chan JK, Freidin A et al. TNF promotes fracture repair by augmenting the recruitment and differentiation of musclederived stromal cells. Proc Natl Acad Sci USA 2010;108:1585-90.

47 Pageau SC. Denosumab. MAbs 2009;1:210-5.

48 Everett BM, Smith RJ, Hiatt WR. Reducing LDL with PCSK9 inhibitors - the clinical benefit of lipid drugs. $N$ Engl J Med 2015;373:1588-91.

Address for correspondence: Professor Sir Marc Feldman, Kennedy Institute of Rheumatology, Botnar Research Centre, Nuffield Dept of Rheumatology Orthopedics and Musculoskeletal Science, University of Oxford, Windmill Road, Headington, Oxford OX3 7LD.

Email: marc.feldmann@kennedy.ox.ac.uk 